\title{
النحت البارز بين الأدوات التقليديه والبرمجه الرقمية
}

ا. ا.ر.د/ محهد محمد عبد الحكيم

أستاذ النحت البارز والميداليه المساعد ـ وكيل الكليه الشؤون التعليم والطلاب

كلية الفنون الجميله ــ جامعة أسيوط

مقدمة :

يعد فن النحت من أقدم الفنون في تاريخ الحضاره الانسانيه وبتتابع العصور تطور الثكل والمحتوى ومن ثم الطرق الأدائيه كما صاحب ذلك مواكبه الادوات والمعددات اللازمه لفن النحت إحتياجات كل عصر على حده حيث إنتقات النقلت الأدوات من العصور القديمه

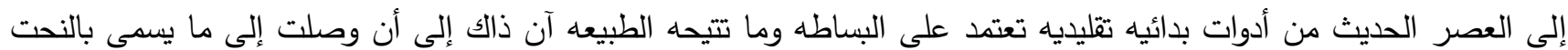

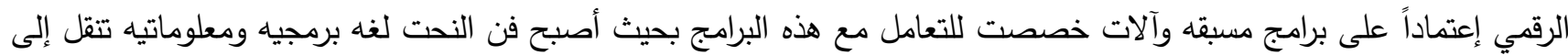
أجهزه الكمبيوتر بواسطه ماسح ضوائي ثلاثي الأبعاد وهذا ما أتاح مظاهر بصريه ومعالجات مبهره لم تكن في السابق وإن كانت

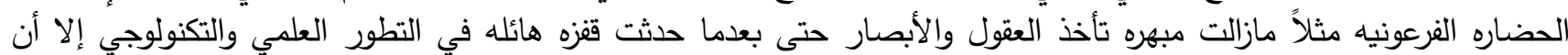

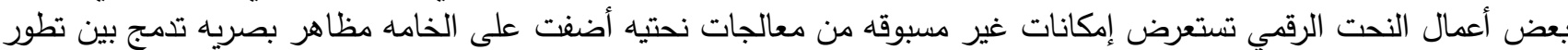

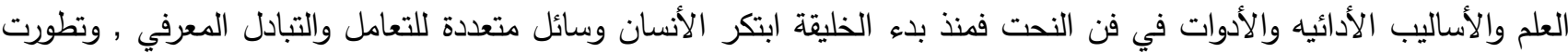

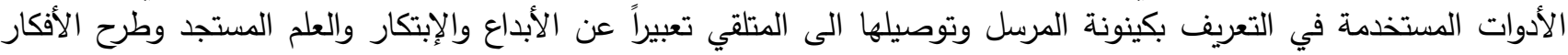

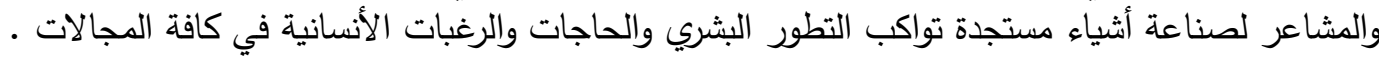

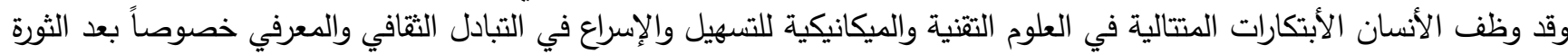
التكنولوجية ,والتي دخلت في جميع مفاصل الحياة المتمثل بتقنية جهاز الحاسوب ,الذي يعتبر مبرمج متكامل بما فياه من تقاتئيات

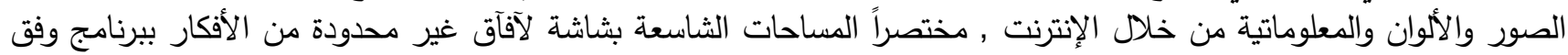

وقد تأثر فن النحت بالتطور سريع الخطى فى كل نواحى الحياة , مما أثر أيضاً بشكل قوى وفعال فى الوسائط الإبداعية للنحات مما

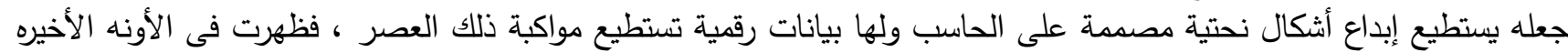
عدة مصطلحات جديده على فن النحت وسرعان ما بدأت فى الإنتثار وربما كان من أهمها هو الطينة الرقمية (Digital clay)

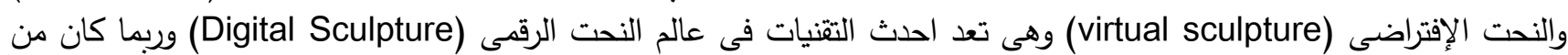

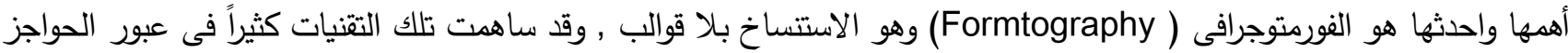

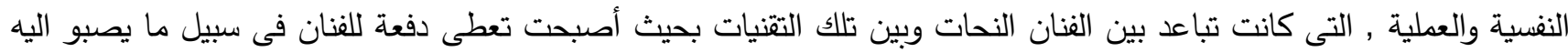

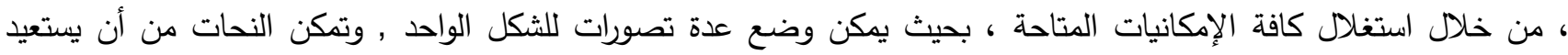

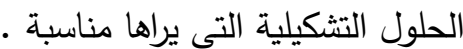

هشكلة البحث: استخدام تكنولوجيا هذا العصر في التهاية التداث تغيرات جذرية في مفاهيم وأساليب التعبير الفني ذات أهمية قصوى

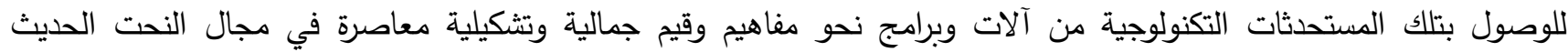

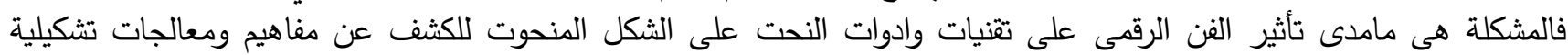

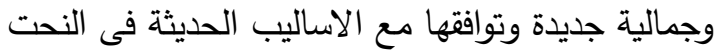
فرض البحث : من خلال استخدام البرمجيات الرقميه في مجال النحت كادوات تكثف مفاهيم ومعالجات تثكيلية وجمالية جديدة

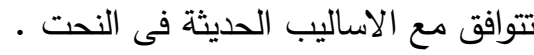
هدف البحث : - التعرف على تأثيرات الوسائط الرقمية- مع وجود الأساليب التقليدية -على الجانب التقنى فى النحت البارز

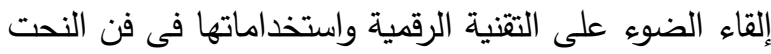

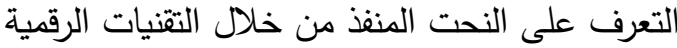

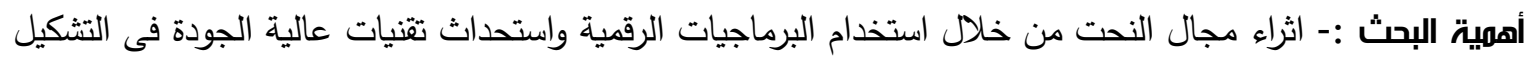

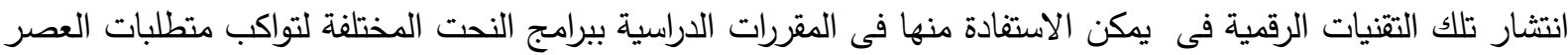

منهجية البحث : الوصفي - تحليلى الأني الدراسة :أستمر الانسان في الستعمال الاداة المباشرة على مر الزمن تطورت من اداة حجرية صوانة الى أداة معدنية أكثر تطورا تحركها

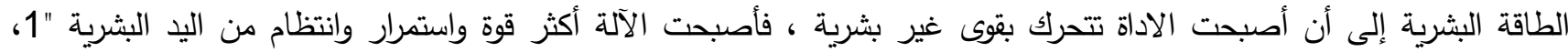

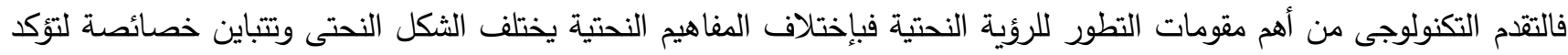
الجانب التقنى فى فن النحت ، ومن ثم ابراز دور الادوات والمعدات الحديثة جعلت النحت ايسر مما سبق وان كان هذا لا يقلل من 
" فالمنحوتات اصبحت لا تستغرق وقتا طويلا ، فكثير من العمل اليدوى مطلوب ، لكن النحاتين يعملون بوسائل أخرى ويتمتعون

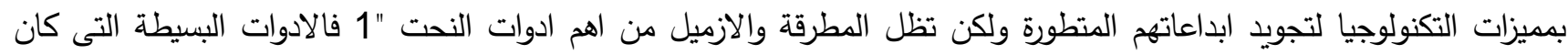

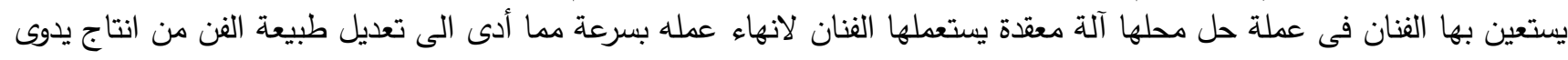

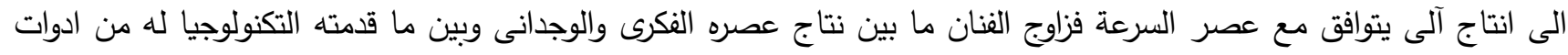

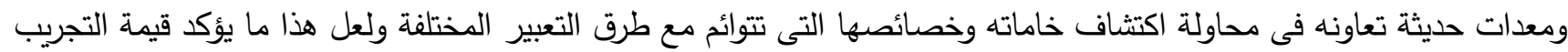

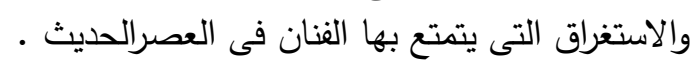

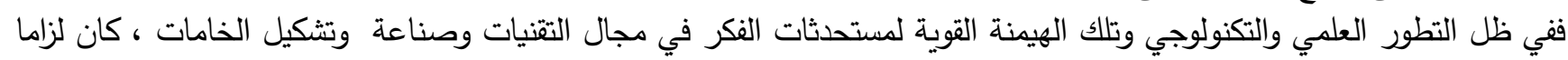

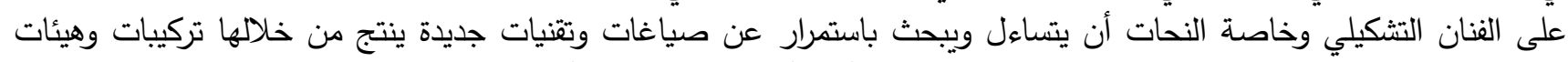

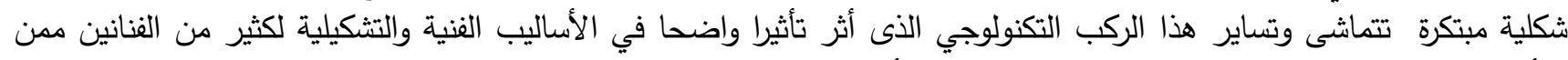

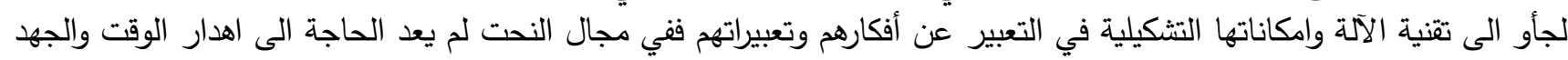

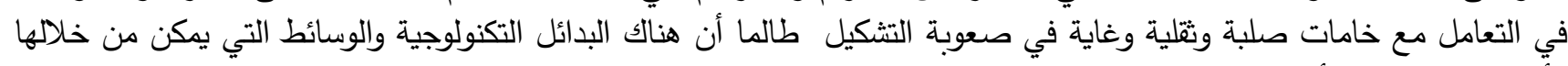

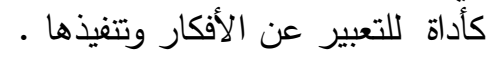

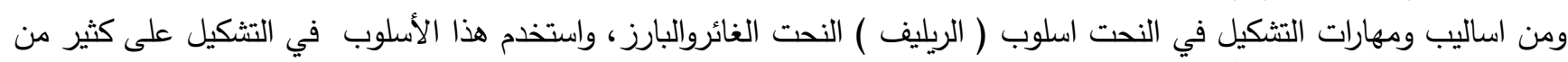

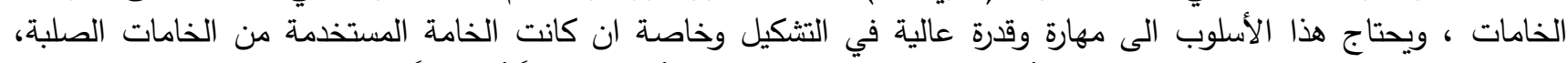

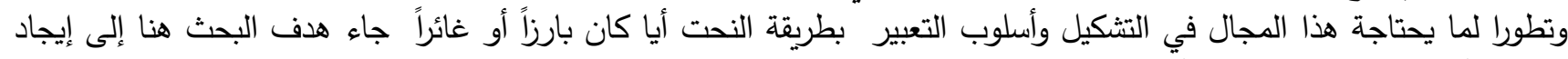

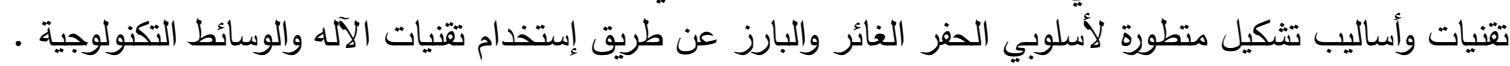

الثورة الرقمية وتطورها: أنشطة المجتمع الإنساني بمختلف أنوفئ أنواعها وأنماط تطور ها ترتبط بتراكم الخبرات والمعارف وتوظيف البيانات والمعلومات لمزيد

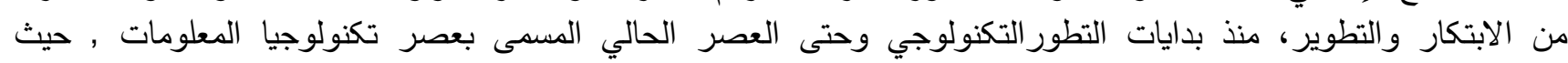

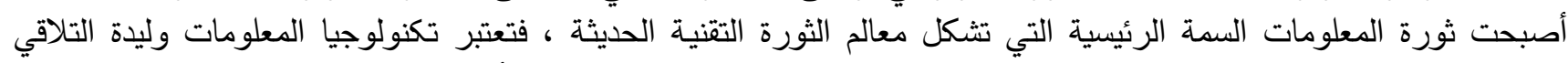

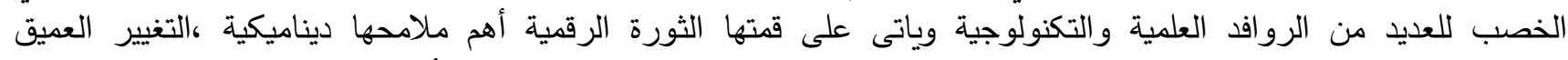

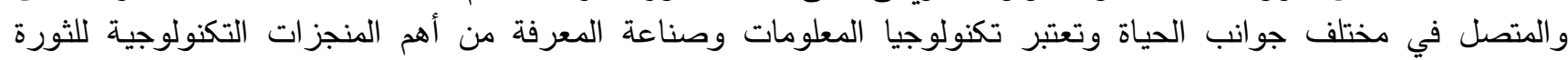
الرقمية.

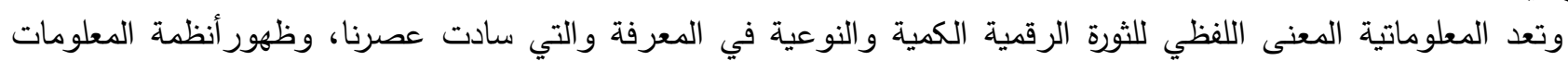

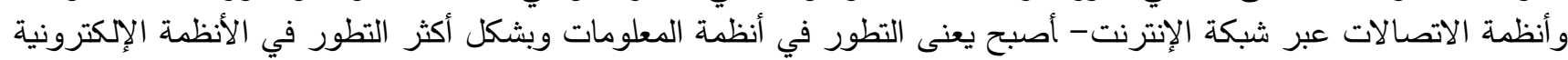

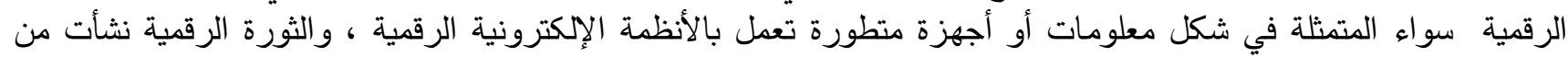

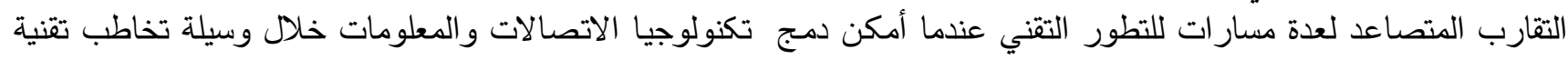

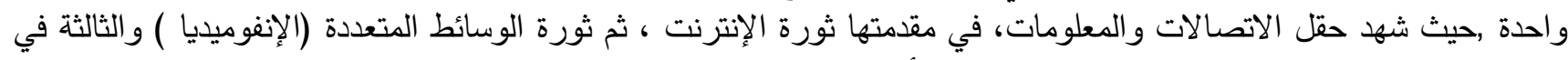

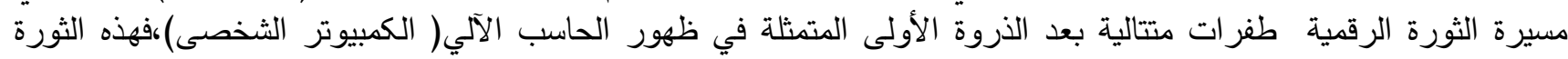

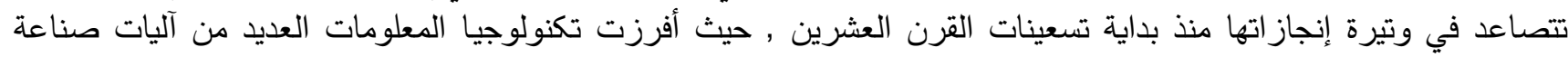

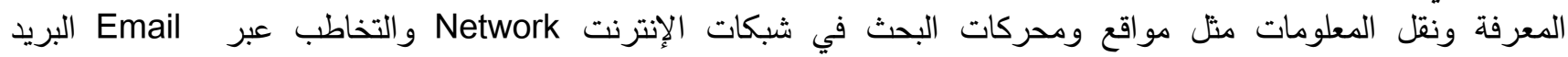
الإلكتروني News Group نظام تبادل المعلومات ، ونظم التعلم عن بعد ويولد أفكار جديدة من خلال الاحتكاك بين الثقافات

المختلفة . الاكترون

وتمثل تكنولوجيا الإككترونيات محرك صناعة المعلومات وتطبيقاتها الواسعة عبر تطور الثورة الرقمية حيث تطور الحاسب الآلي

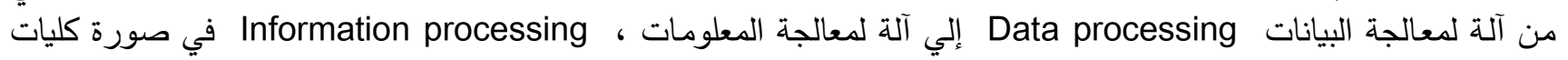

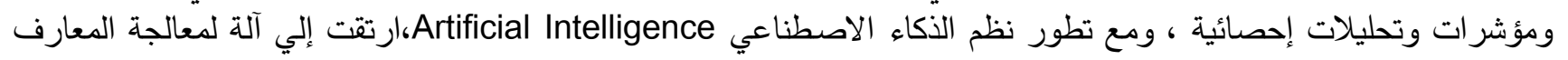

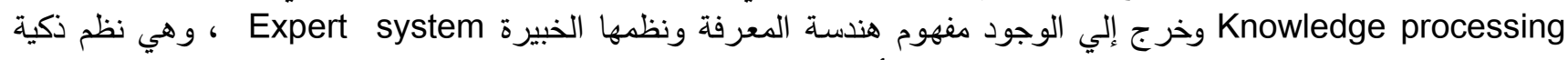

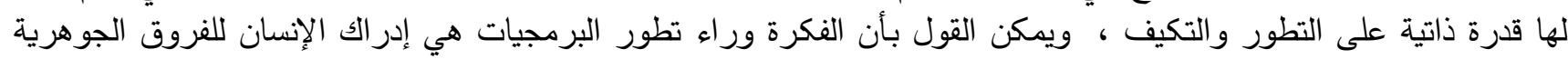

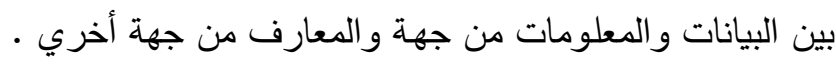
ومنالذكاء الاصطناعي إلي العوالم المصطنعة المركبة تكنولوجيا الواقع الافتر اضي

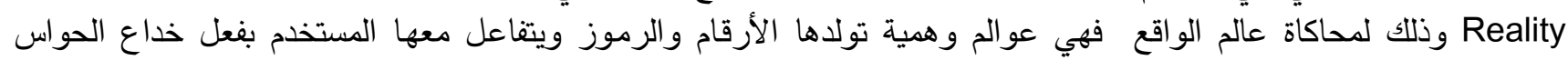

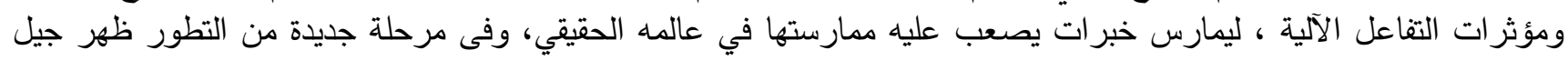

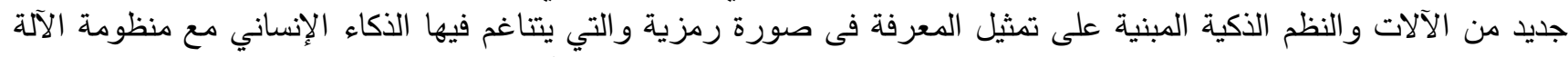

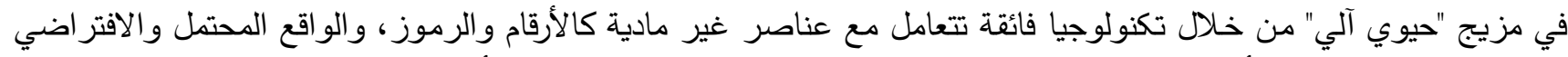

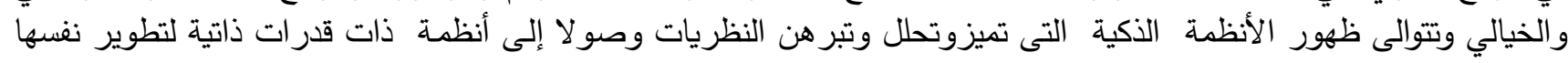


مع المستجدات ، فالفن الرقمي هو شكل من أثكال الفن المعاصر حيث يتم إنثاء العمل الفني إما جزئيا أو كليا مع أجهزة الكمبيوتر

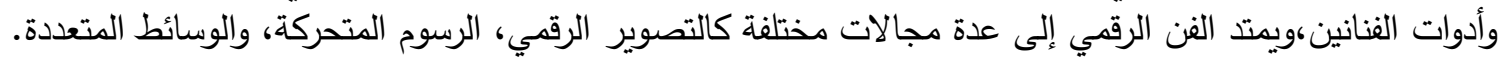

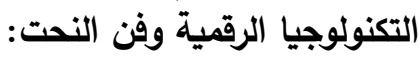

عرف العصر الحديث بعصر المعلومات الو عصر الكبات الكبيوتر هذا الابتكار الذى غير وجه الحياة الانسانية ، فيعد الكمبيوتر من اهم

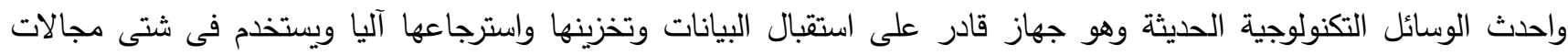

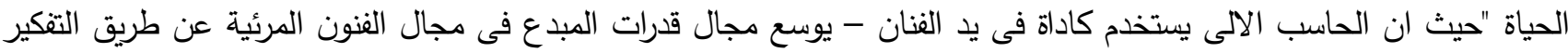

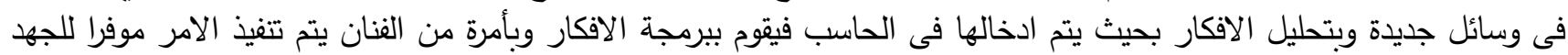

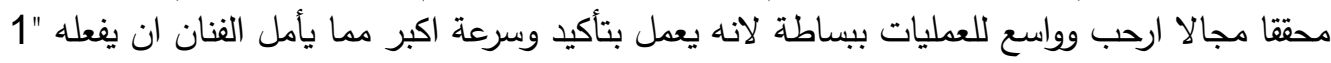

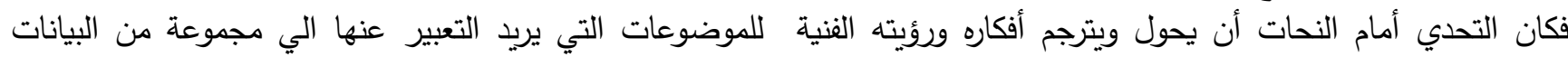

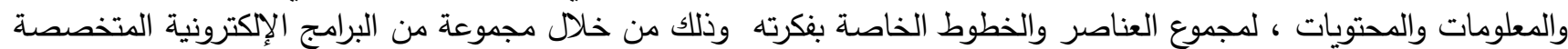

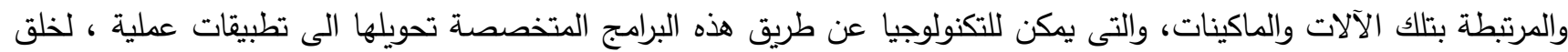

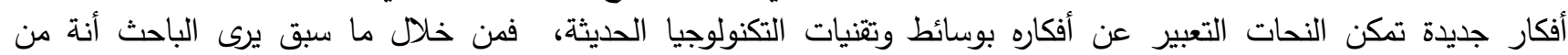

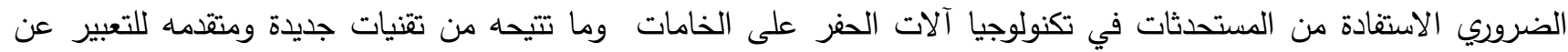

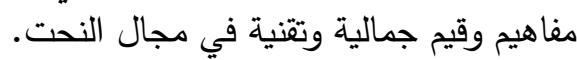
التحكم الرقمى : التحكم الرقمى هو التحكم فئ ماكينات العدد بواسطة الأرقام , حيث تستقبل الماكينة الأوامر من وحدة تحكم خاصة وتقوم بتنفيذها ـ وتقبل الماكينة المعلومات فى صورة شفرات coded information من وحدة التحكم , وتقوم بالتتفيذ طبقاً للأوامر

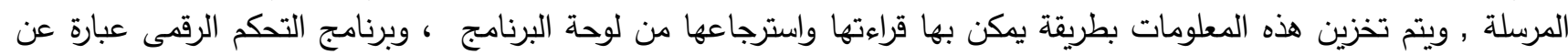

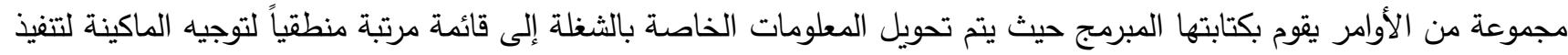

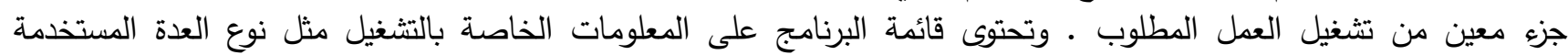

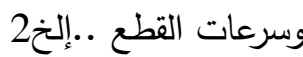
ولقد كان لظهور تقنية التحكم الرقمى بمثابة التحول الجذرى فى طريقة التحكم فى ماكينات العدد , وذلك استجابة لما بدأ جلياً من

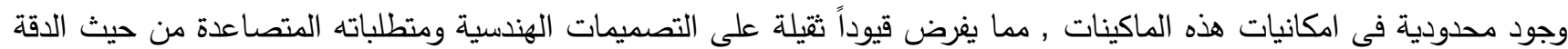

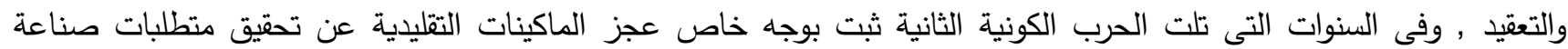

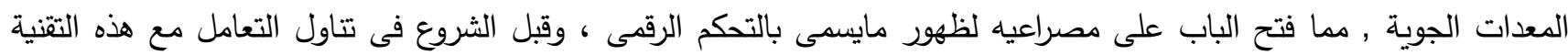

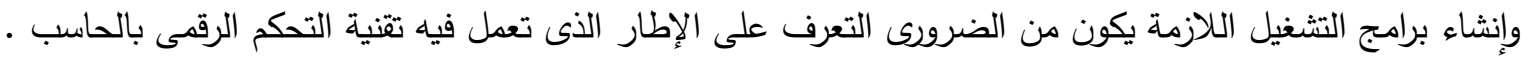

أنواع نظم التحكم الرقهى :

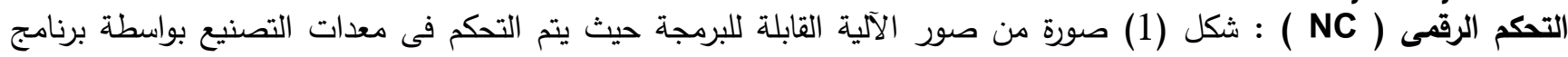
خاص بالقطعة المراد انتاجها , ويكون البرنامج فى شكل أرقام وحروف ورموز , ويحفظ على هيئة شريط مثقب تتم قراءته بواسطة

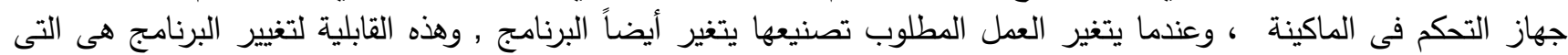

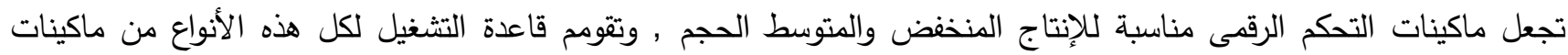

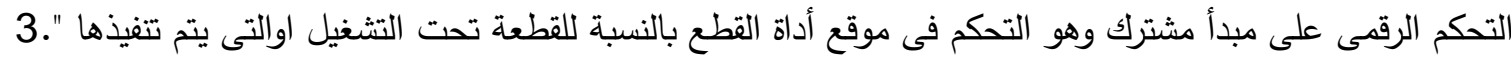
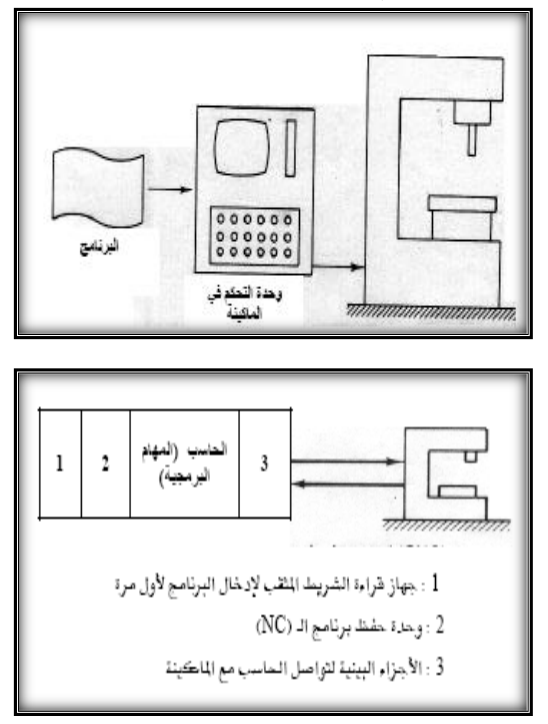

$2 /$ http://www.flong.com/projects/aves

3 http://www.anamuhands.net/2018/07/nc-cnc.html

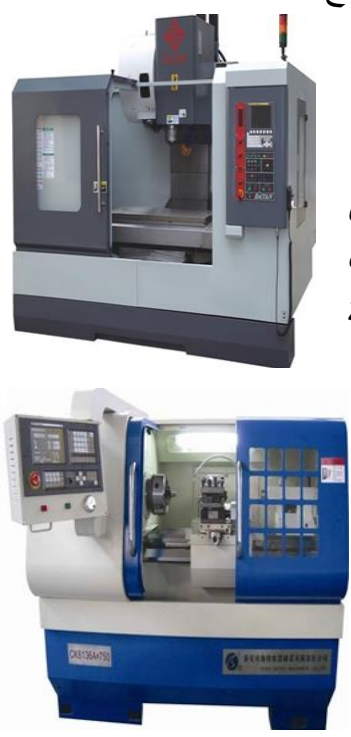

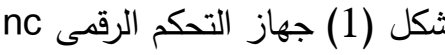

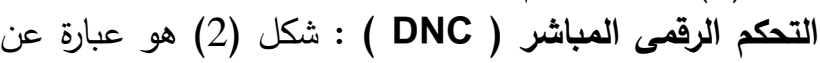

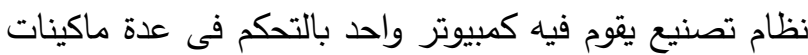

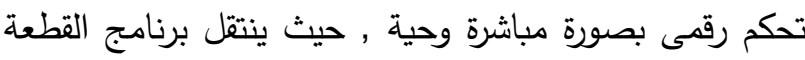
المعينة المراد إنتاجها من ذاكرة الكمبيوتر مباشرة إلى ماكينة

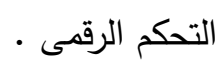

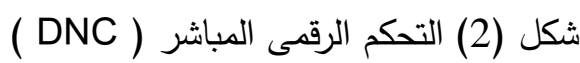

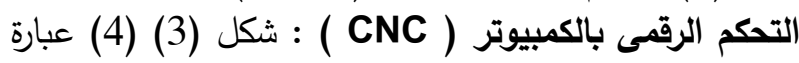

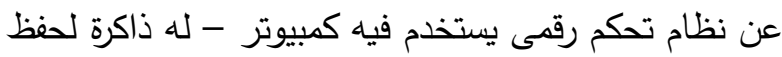

1 ادوارد لوسى سميث : الحركات الفنية منذ 1945 ، شركة لوتس للطباعة والنشر - 1997، ص 130 
البرامج التى تسجل فيه - للتحكم فى ماكينة التحكم الرقمى , ويمثل الكمبيوتر جزء لا يتجزأ من الماكينة , ويمكن برمجة ماكينة

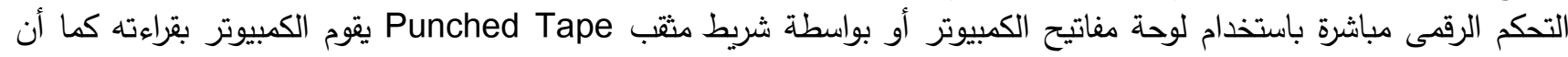

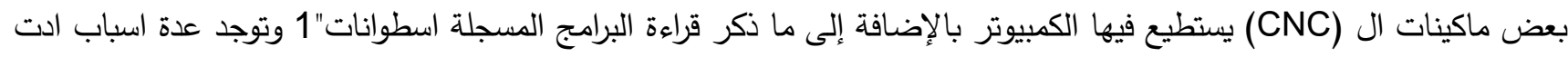

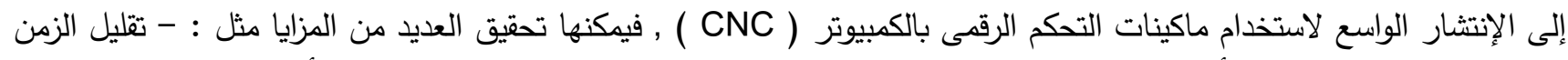

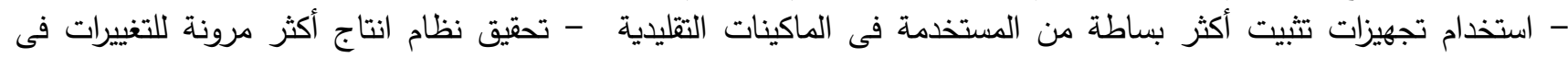

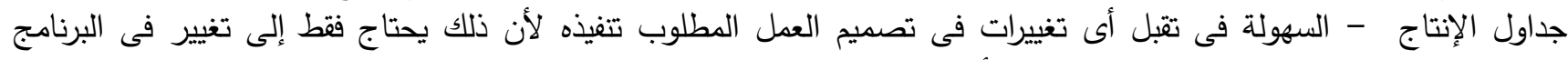

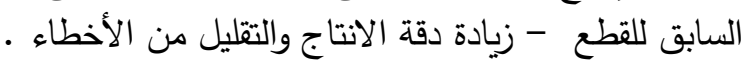

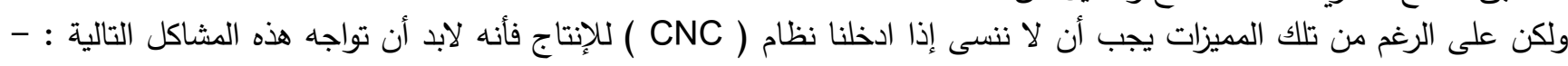

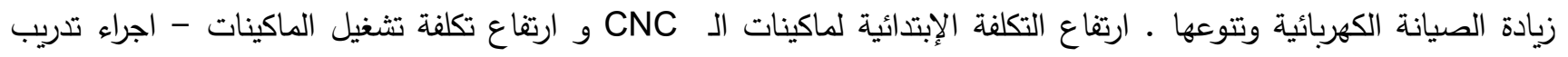

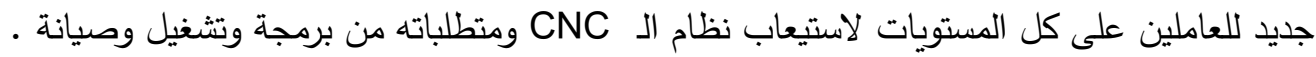
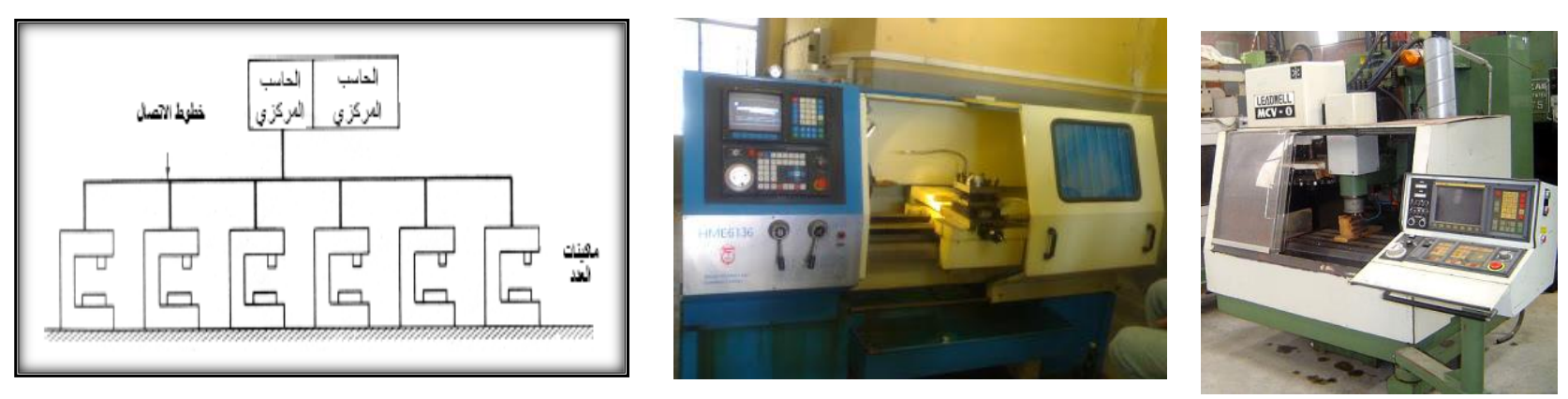

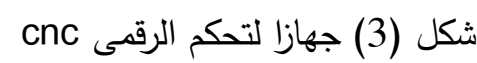
تشمل ماكينة أل CNC علي وحدة نظام تلضى لتفن وحدة التحكم ووحدة المراقبة ووحدة لتوجيه آليات التشغيل وفقا لتصميم مسار الآلة

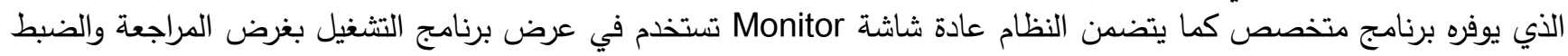

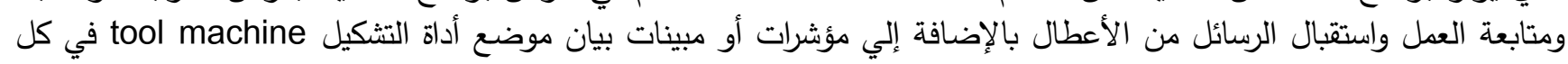

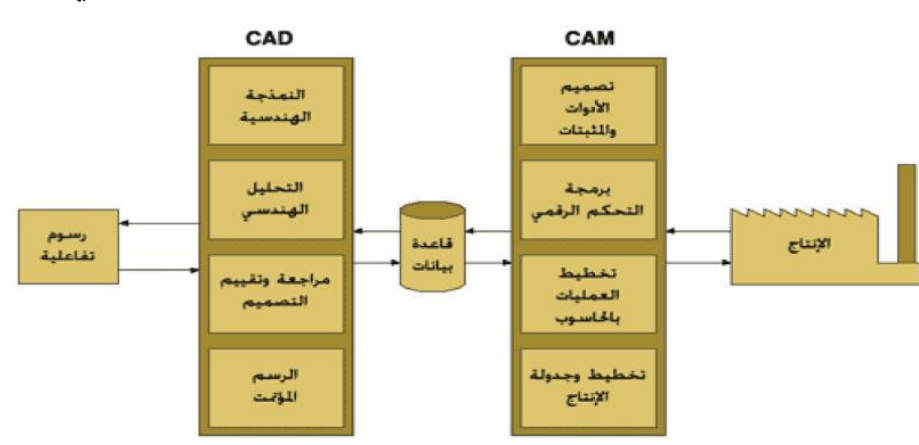

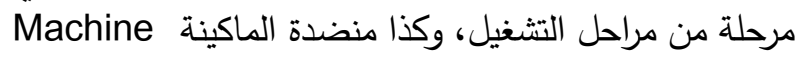
Table البرنامج وتخزينه وكذا جهاز أو برنامج تشخيص الفض الأعطال Diagnostics

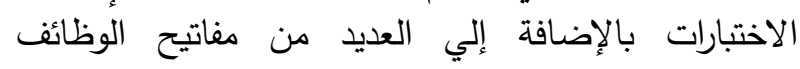

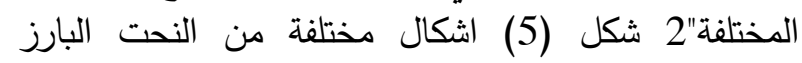
والغائر بالطريقة النحت الرقمى

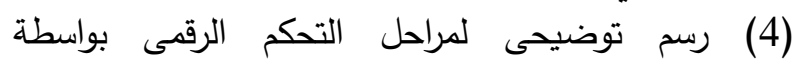
الكومبيوتر
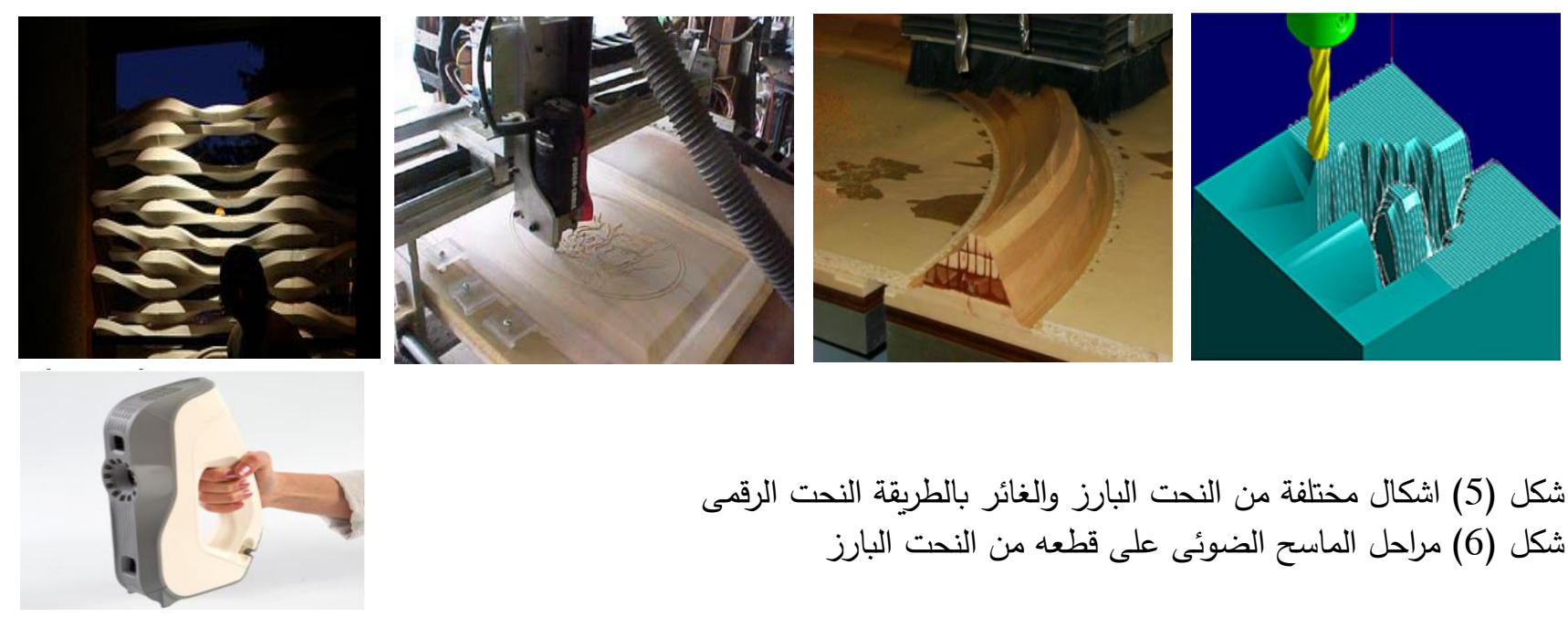

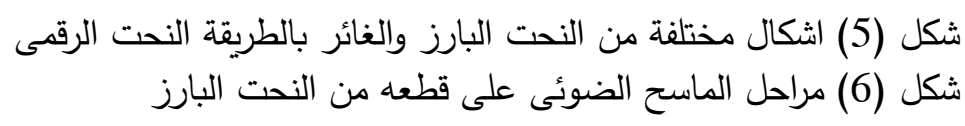




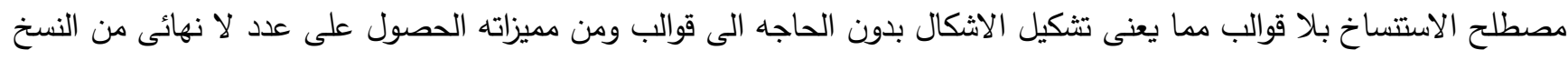

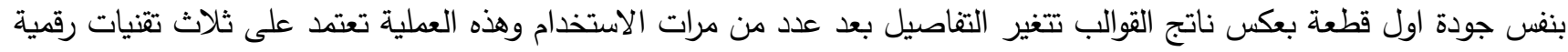

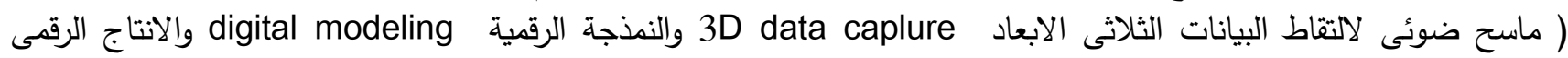
digital production

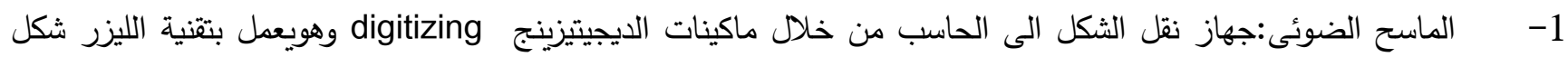

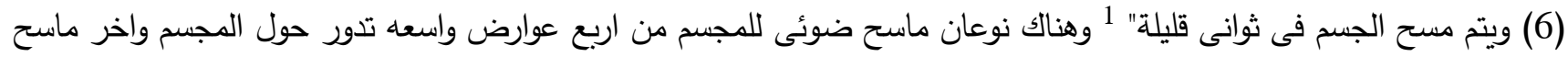

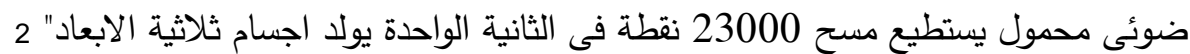

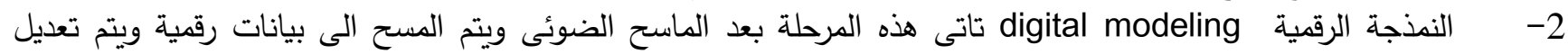

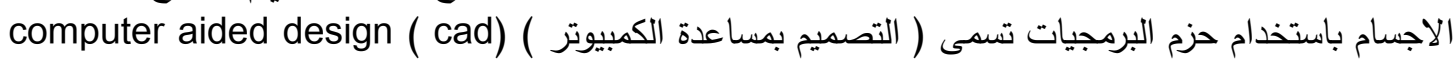

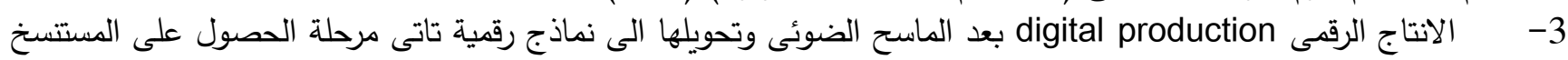

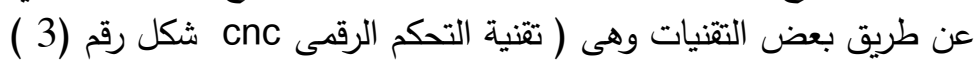

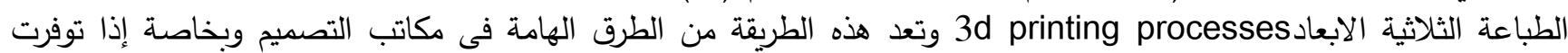

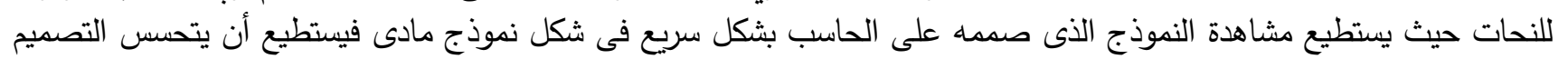

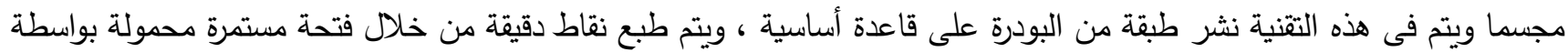

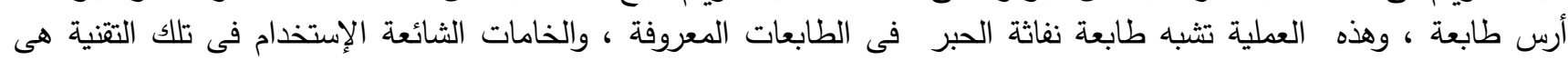

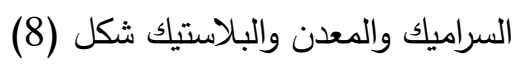
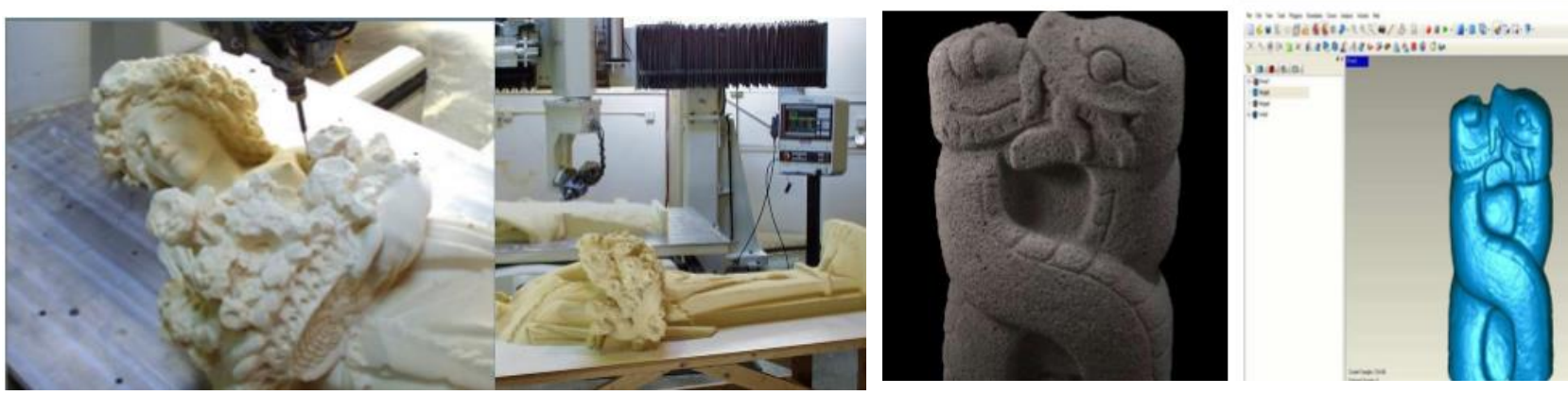

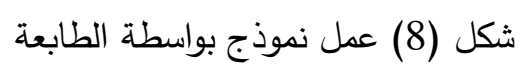

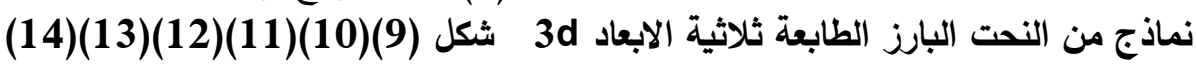
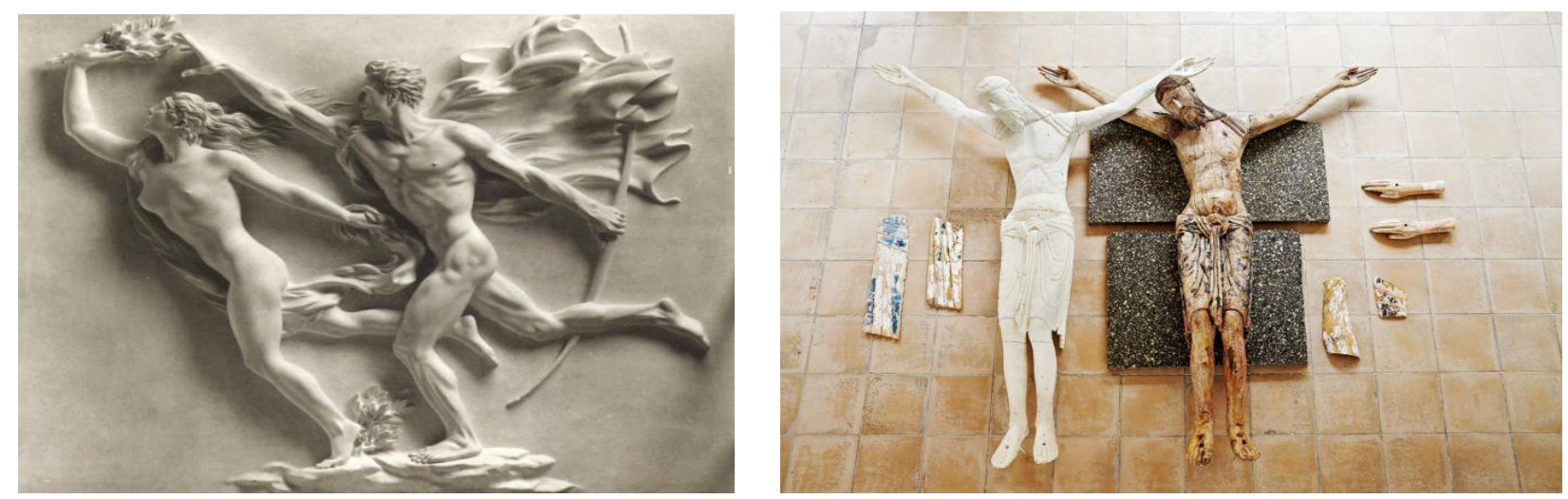

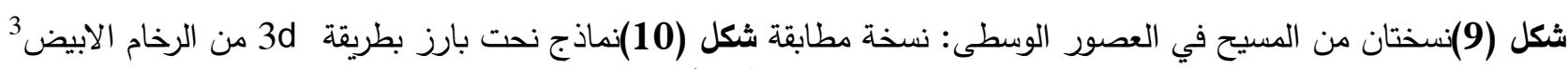
خشبية بالكمبيوتر (على اليمين)، ونموذج مطبوع العن بان الطباعة ثلاثية الأبعاد 4

1 Artec Shapify Booth-Body Scanner https://www.laserdesign.com/products/artec-shapify-booth/ 28 /3/2017 2 Artec Eva \& Eva Lite 3D Scanner Body Scanner- Economy Scanner- Portable Scanner -

https://www.laserdesign.com/products/artec-eva-3dscanner

3 https://arabic.alibaba.com/g/make-relief-sculpture.html

4 https://zahma.cairolive.com/ 

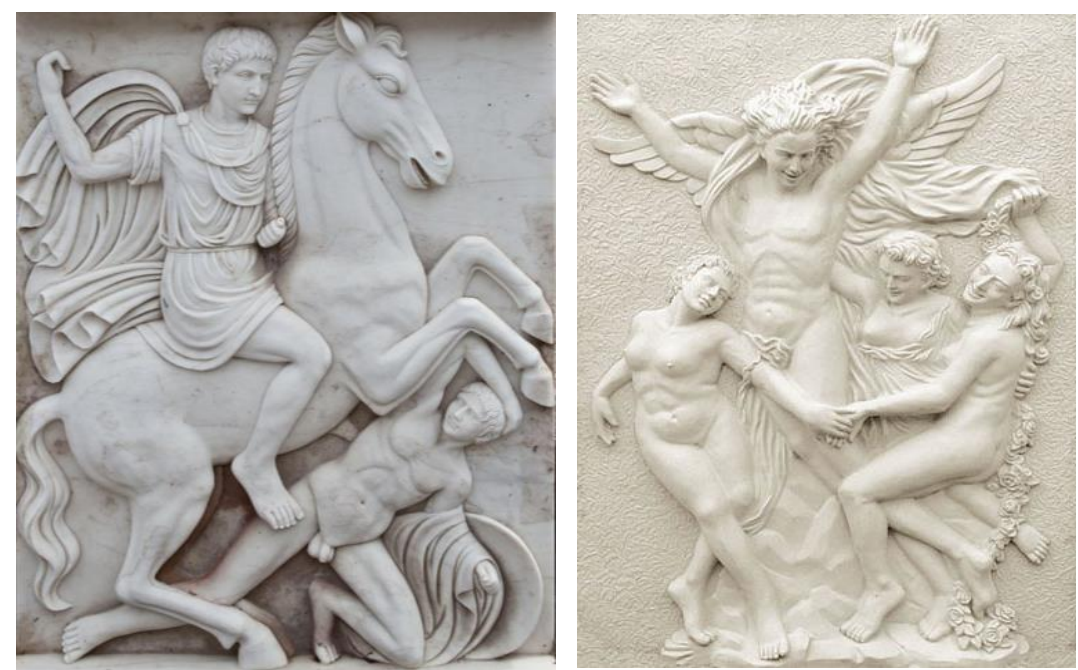

$$
\text { شكل (11) يمين نمت باذج بطريقة 3d من الرخام }
$$

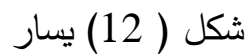

نماذج نحت بارز بطريقة

الابيض 1

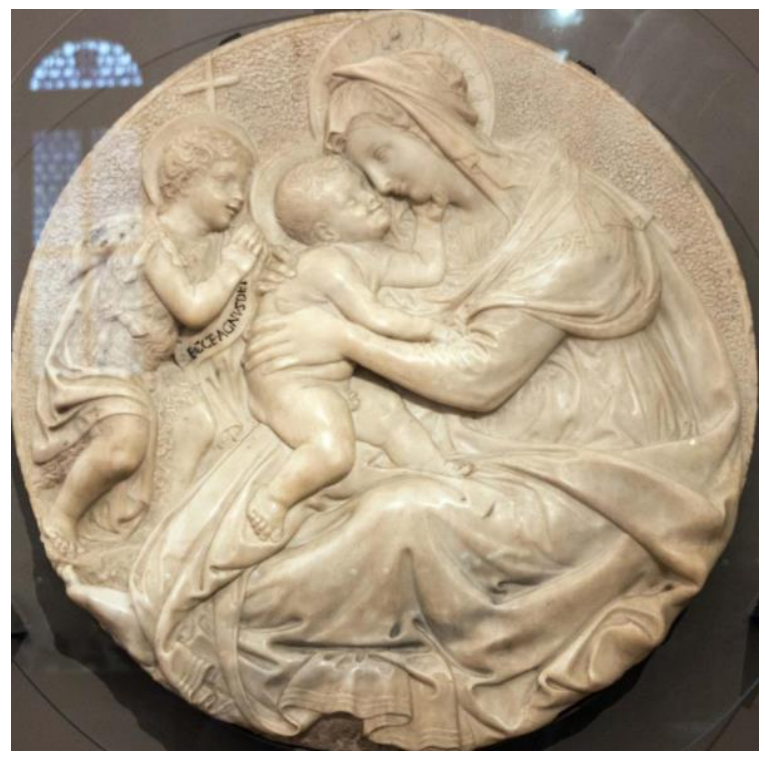

وبما ان فن النحت تأثر بمعطيات التكنولوجيا والتقدم العلمى لارتباطة

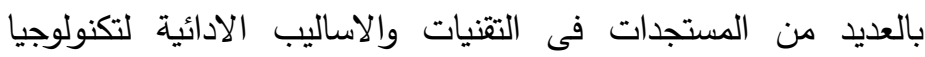

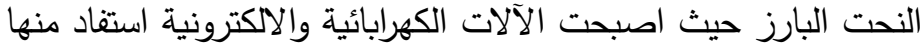

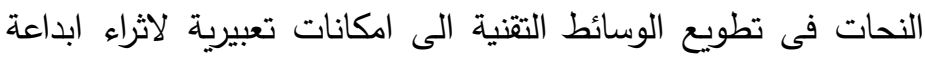

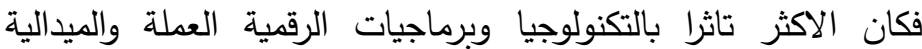

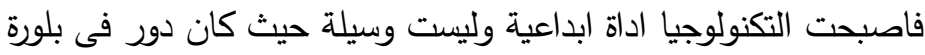
وترجمة الخطوط والعناصر محتوى الفكرة الى هيكل وبناء وجسد تم

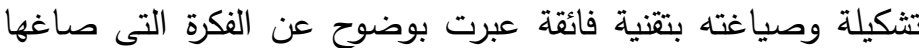

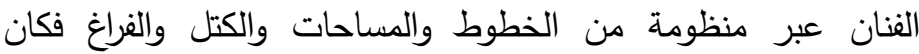
للتكنولوجيا النحت مجموعة من التقنيات واساليب التثكيل على سطح ولك

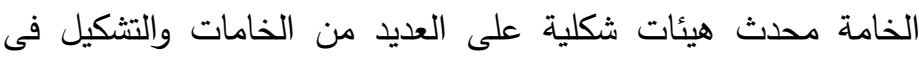
مجال النحت البارز والغائر على الميدالية والعملة اشتمل على تقنيات التيات

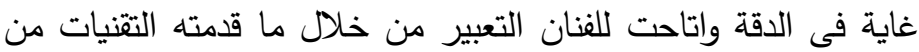

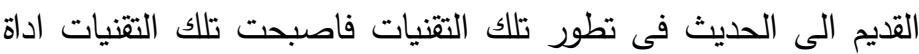
للتعبير من خلال الوسائل التكنولوجية المستخدمة قديما وحديثا في (13) نحت بطريقة 3dميدالية مريم العذراء (جرانيت)2

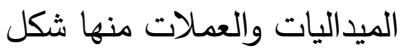

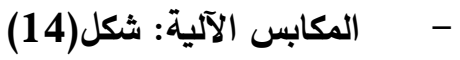
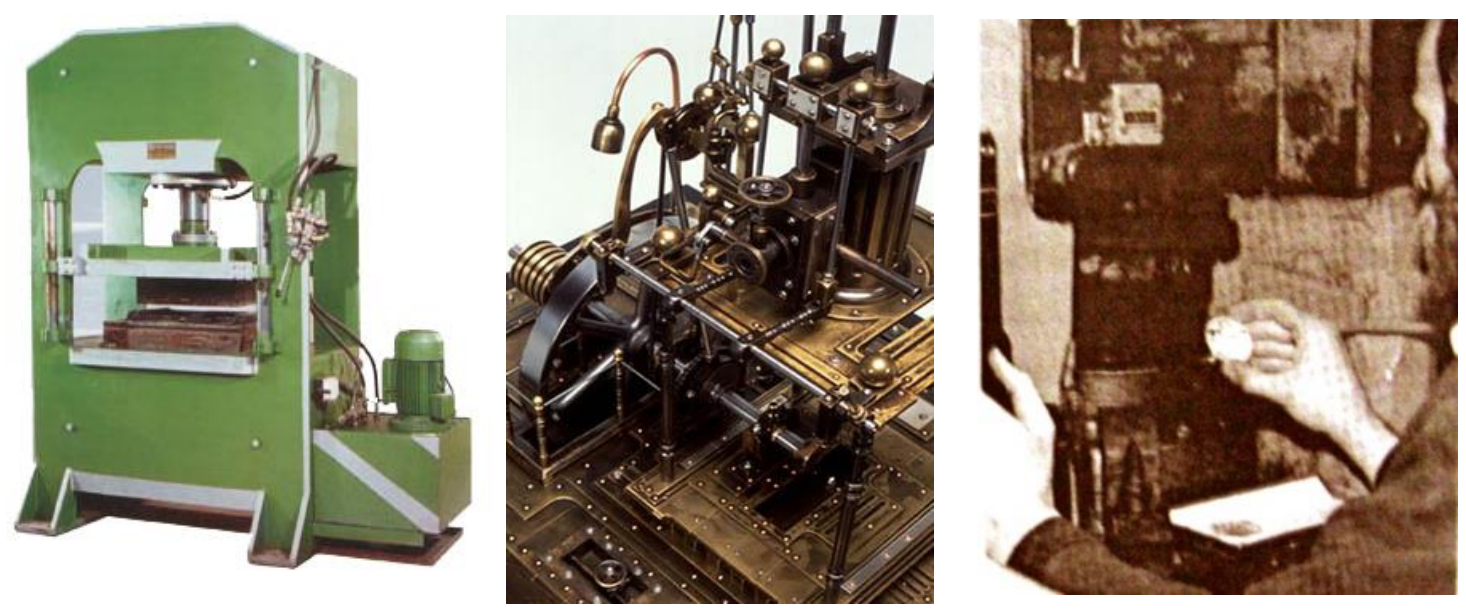

شكل (14) مرحلة سك (14) العملات بالمكبس الالى الكهربي"

ب) بهاز البانتوجراف:

شكل (15) (15) 

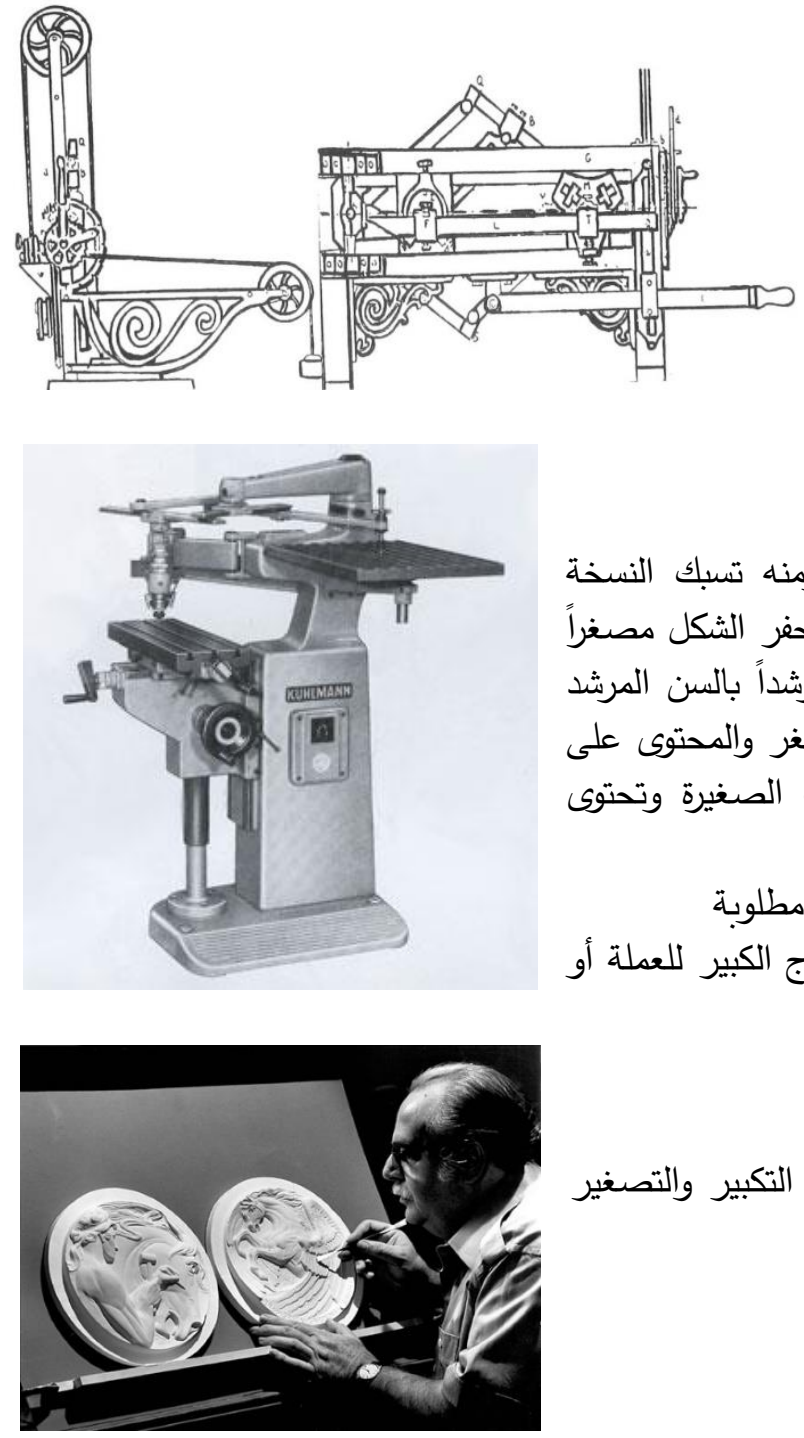

شكل(15) بانتوجراف براسارات اليدوي ويوجد بدار سك العملات

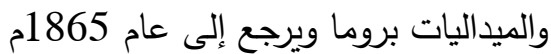
- جهاز البانتوجراف الآلي أو الأوتوماتكات وهذات وهذا الجهاز يقوم بكل

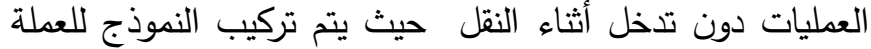

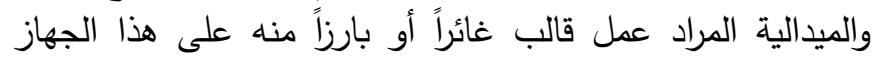

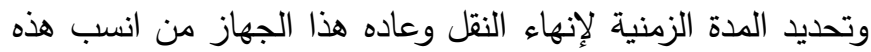

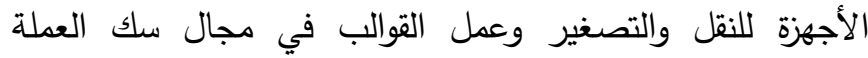
والميدالية شكل(16)

شكل(16)بانتوجراف افقآ يتكون من وحدتين رئيسيتين"(1).

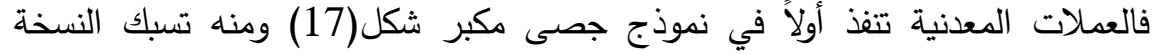
المعدنية التي توضع في ماكينة البانتوجراف والتي تقوم بدورها تقوم بحفر الثكل فئل مصغراً

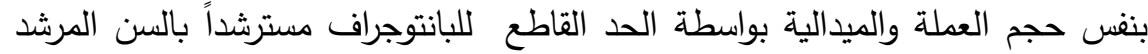

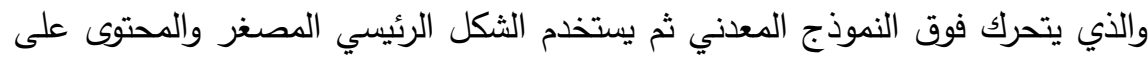

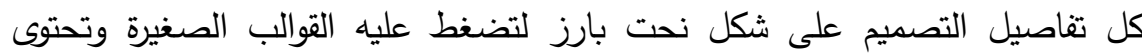
ماكينة البانتوجراف على الأجزاء التالية:

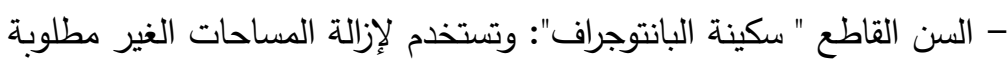

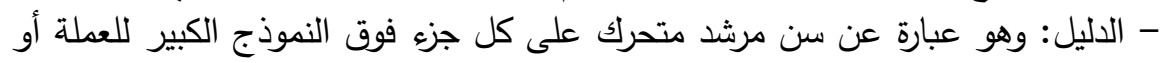

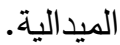
- منجلة كبيرة: لتوضع عليها النماذج الكبيرة للعملة أو الميدالية. - منجلة صغيرة: ليوضع عليها قالب التشغيل المراد تصغيره.

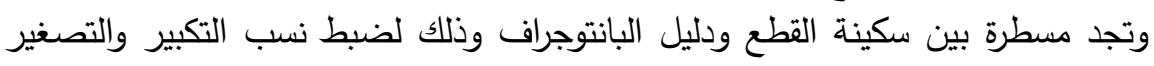

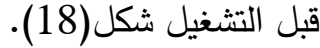

$$
\text { شكل(17)عمل نموذج جصى لميدالية }
$$

شكل (18) الميدالية إثناء تصغيرها بالبانتوجراف الكهربي الحديث جهاز الحفر بالشرارة الكهربائية المستمرة:

شكل(19) تمثل ماكينة الحفر بالشرارة الكهربائية المستمرة spark Erosion Machine نوع متطور من الأساليب الميكانيكية الحديثة المستخدمة في مجال العملة والميداليات إذ تستطيع أن تؤدى بشكل سريع العديد من العمليات التي تستخدم في فن العملة
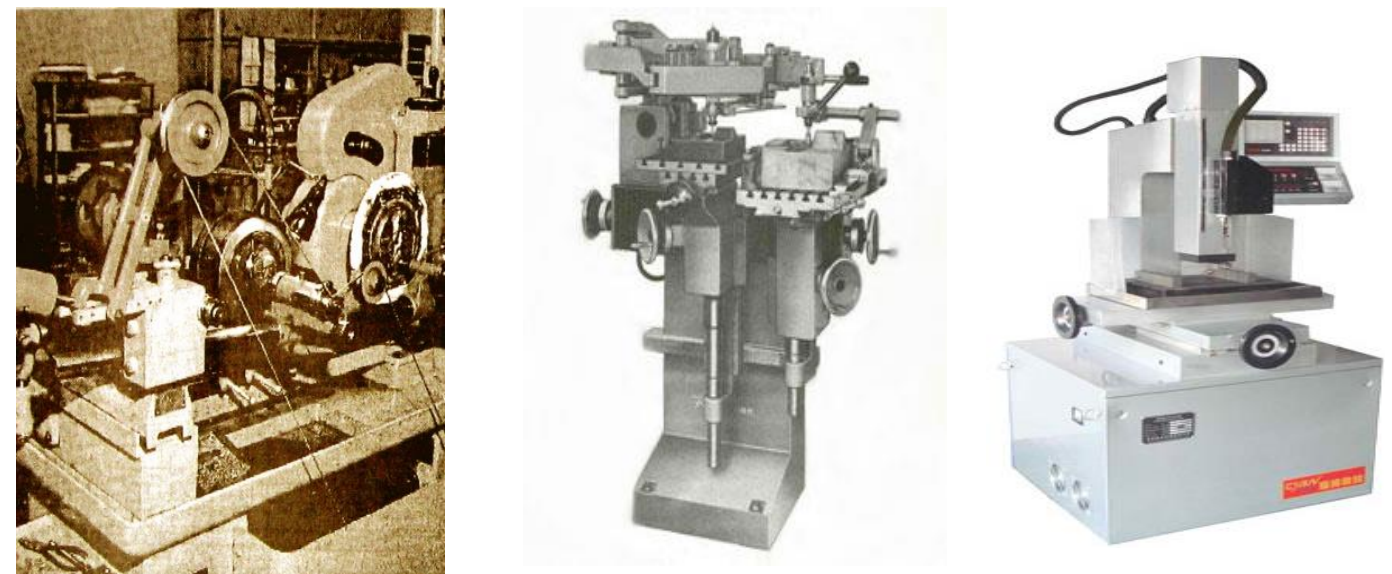

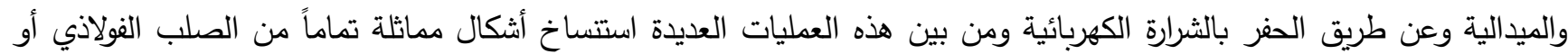

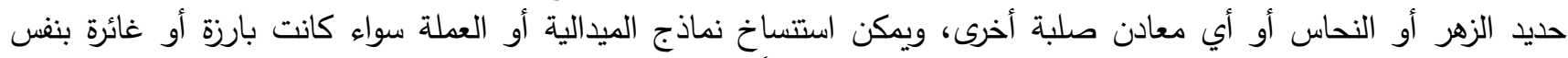

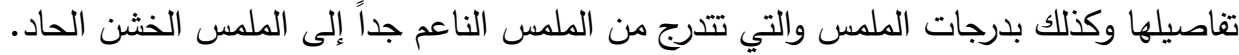




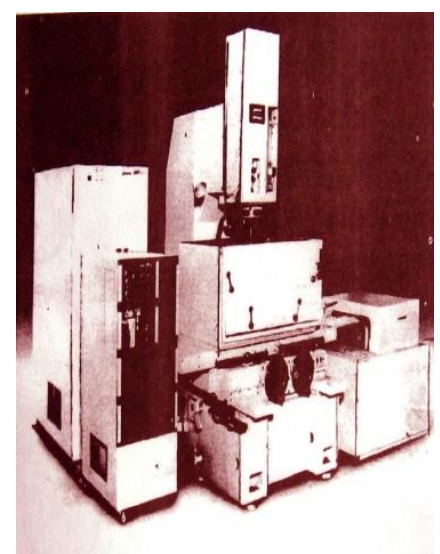

شكل (19) ماكينة الحفر بالشرارة الكهربائية المستمرة وتعتبر من احدث الأجهزة المستخدمة في بالبالي

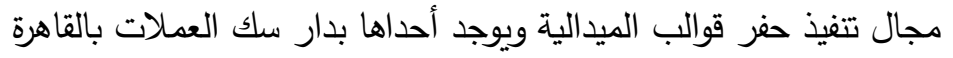

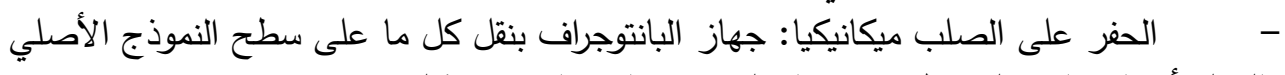
للعملة أو الميدالية على قطعة من الصلب معده لهذا الغرض شكل جلئل

شكل(20) مراحل الحفر علي الصلب تصنيع العملة والميدالية بعمل التصميم من قبل التبل الفنان بالقلم الرصاص هأو صورة فوتوغرافية باستخدام البرامج الرقمية شكلة (21)

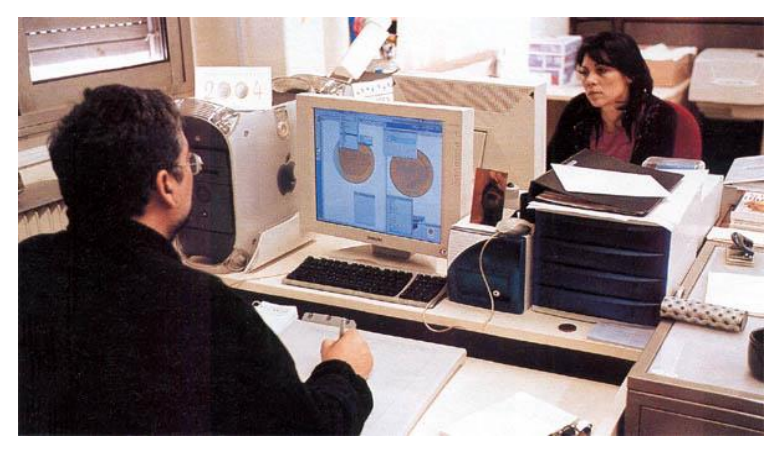

شكل(21) مرحلة الرسم للنموذج

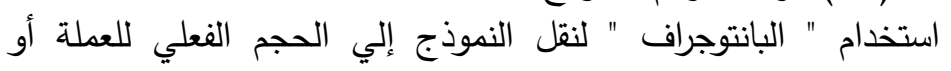

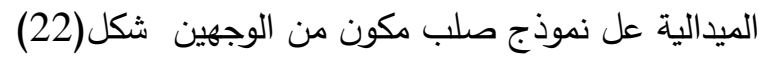
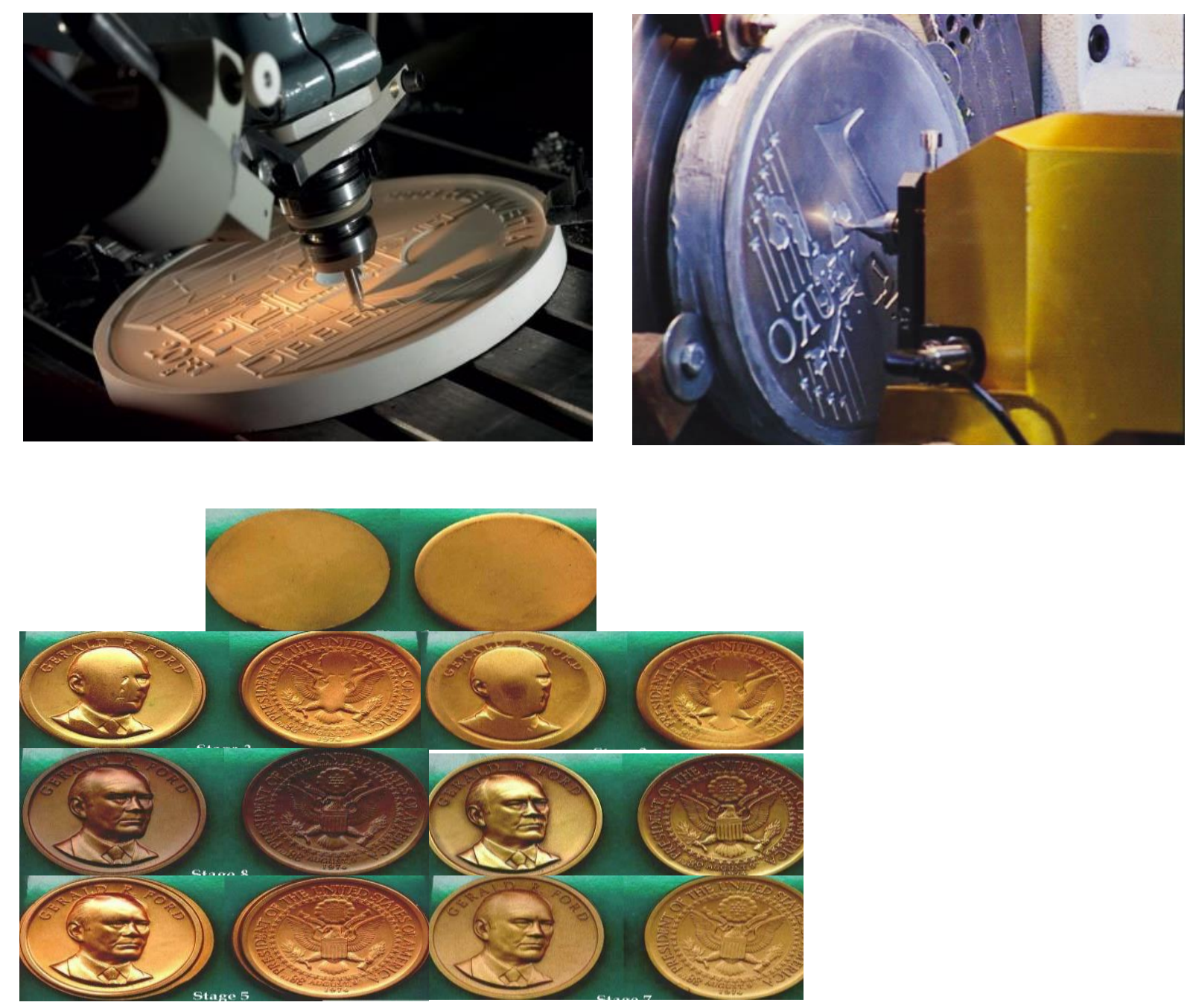


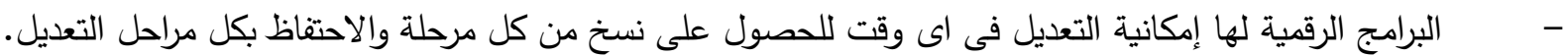

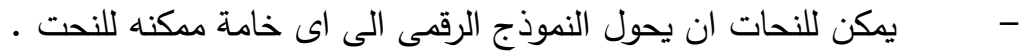

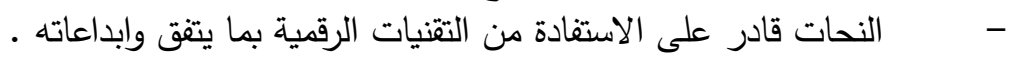

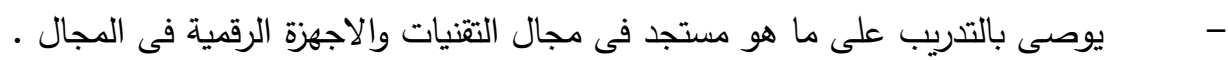

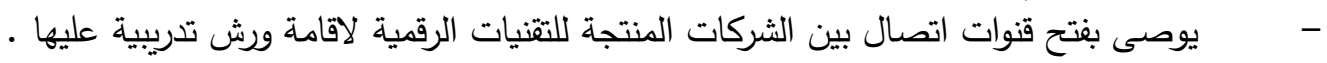

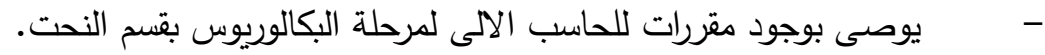

2- أحمد وحيد مصطفي : مقتطفات من كتاب (تقنيات مستحدثة في التصميم والتصنيع بالحاسبات) دار الفكر العربي 2005

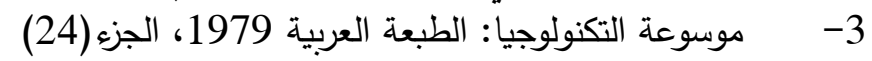

4- -عفيف البهنسى : من الحداثة إلى ما بعد الحداثة فى الفن ، دار الكتاب العربى دمشق ، ط1، 1997

5- Dona.Z.Meilach- Contemporary Stone Sculpture.(London George Allen \&Unwim Ltd 1970)

6- $\quad$ /http://www.flong.com/projects/aves

7- $\quad$ http://www.anamuhands.net/2018/07/nc-cnc.htm

8- http://engsciences.blogspot.com/2014/07/blog-post_958.html

9- $\quad$ https://www.laserdesign.com/products/artec-shapify-booth/ 28 /3/2017

10- $\quad$ Artec Eva \& Eva Lite 3D Scanner Body Scanner- Economy Scanner- Portable Scanner

11- https://arabic.alibaba.com/g/make-relief-sculpture.html

12- https://www.laserdesign.com/products/artec-eva-3dscanner

13- https://zahma.cairolive.com

14- https://arabic.alibaba.com/product-detail/marble-lady-wall-sculpture-

60217906335.html?spm=a2700.8699010.29.89.ca572fa6uSjmAn

15- https://arabic.alibaba.com/product-detail-img/-60194669567.html 